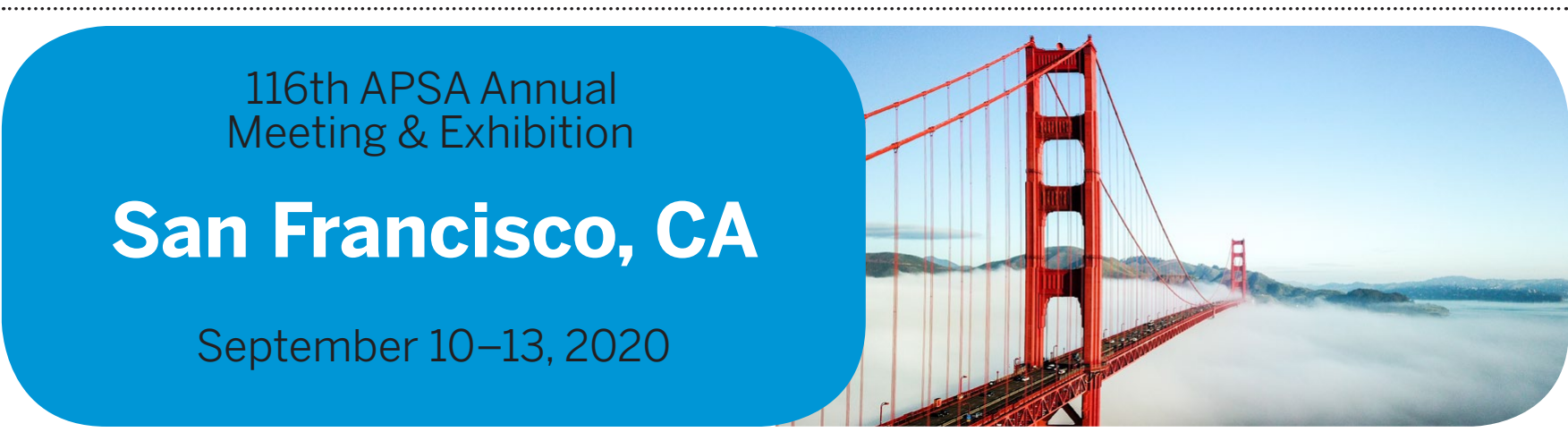

\title{
Democracy, Difference, and Destabilization
}

J oin us in San Francisco, CA, on September 10-13 for the 116th APSA Annual Meeting. The meeting will address the latest scholarship in political science while exploring the theme, "Democracy, Difference, and Destabilization." APSA and the 2020 program chairs, Efrén Pérez, UCLA, and Andra Gillespie, Emory University, look forward to your participation.

\section{LOCATION}

The 2020 APSA Annual Meeting will take place in San Francisco from September 10-13 (off Labor Day) at the Hilton Union Square, Parc 55, Hotel Nikko, and Westin St. Francis. Be sure to book your APSA hotel early to take advantage of the group rate. See more: https://connect.apsanet.org/ apsa2020/housing/.

\section{REGISTRATION}

Registration is now live! Early bird registration closes on July 9, 2020. Registration includes access to all panels from Thursday to Sunday (including plenaries and breaking news panels), access to the opening reception on Thursday night, access to section business meetings and receptions, access to the APSA Exhibit Hall and iPosters, and access to the eJobs
Placement Service and the TLC-at-APSA mini-conference after additional sign-up. For more information, visit https://connect. apsanet.org/apsa2020/.

\section{CONFERENCE PROGRAM}

Conference sessions are developed by APSA program chairs, divisions, and related groups. The preliminary program will be available at the end of May. In addition to the educational sessions, meeting highlights will include the presidential address by Paula McClain, Duke University; the opening reception; career placement; the APSA awards ceremony; APSA section and partner meetings and receptions; and the APSA Exhibit Hall. See the preliminary schedule-at-a-glance: https://connect.apsanet.org/apsa2020/ schedule-at-a-glance/.

\section{CODE OF CONDUCT}

The APSA Annual Meeting and related regional political science meetings are convened for the purposes of professional development and scholarly and educational interchange in the spirit of free inquiry and free expression. Harassment of colleagues, students, or other conference participants undermines the principle of equity at the heart of these professional fora and is inconsistent with the principles of free inquiry and free expression. Consequently, harassment is considered by APSA to be a serious form of professional misconduct. Read the full policy: https://connect. apsanet.org/apsa2020/code-of-conduct/.

\section{TRAVEL GRANTS}

APSA provides travel grants to assist some members in attending the annual meeting. APSA members who are US graduate students, international graduate students studying in the US, unemployed, or international scholars are eligible to apply. If selected, recipients must pre-register for the APSA Annual Meeting to be able to receive travel grants. For more information visit: https://connect.apsanet.org/apsa2020/ travel-grants-3/
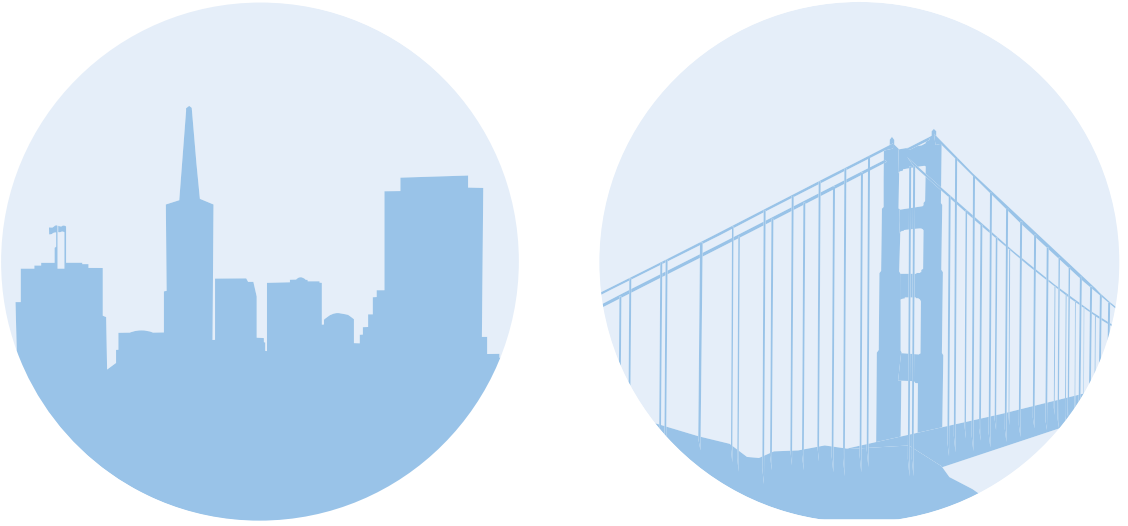